\title{
An economic analysis of mixing wastes
}

\author{
Rob F. T. Aalbers • Herman R. J. Vollebergh
}

Received: 3 February 2006 / Accepted: 3 March 2007 / Published online: 16 May 2007

(C) Springer Science+Business Media B.V. 2007

\begin{abstract}
Using a general equilibrium model with heterogeneous waste, this paper studies optimal waste policy when households have to exert separation effort to produce homogeneous waste streams suitable for recycling. Our model explicitly allows for changes in the composition (quality) of waste streams depending on how much effort households are willing to spend on separating different types of waste. Accordingly, we are able to generalize some earlier contributions to the waste management literature and demonstrate that with both mixing and effort included, a first-best optimum is feasible under reasonable conditions. In particular, we find that a (modified) deposit-refund system still provides the optimal incentives to guide recycling as well as legal disposal (landfilling) and illegal dumping. Both the number and level of taxes and subsidies needed to reach the first-best depend crucially on the socially optimal level of dumping as well as the socially optimal composition of the mix.
\end{abstract}

Keywords Economics of waste - Recycling - Environmental taxes and subsidies · General equilibrium theory

\section{JEL Classification $\mathrm{H} 21 \cdot \mathrm{H} 23 \cdot \mathrm{Q} 53$}

\section{Introduction}

Household waste is heterogeneous and consists of a wide variety of waste streams such as paper, glass, organic waste, plastics, textiles, small chemical waste, etc. In order to recycle

We are grateful to two anonymous referees, Leon Bettendorf, Elbert Dijkgraaf, Don Fullerton and Matthieu Glachant for constructive comments and useful discussions on an earlier version of this paper.

R. F. T. Aalbers

Stichting voor Economisch Onderzoek, Roeterstraat 29, Amsterdam 1018 WB, The Netherlands

H. R. J. Vollebergh $(\bowtie)$

Department of Economics and Tinbergen Institute, Erasmus University Rotterdam, P.O. Box 1738, Rotterdam 3000 DR, The Netherlands

e-mail: vollebergh@few.eur.nl 
Fig. 1 Waste supply and recycling of municipal waste in the Netherlands (in millions of tons)

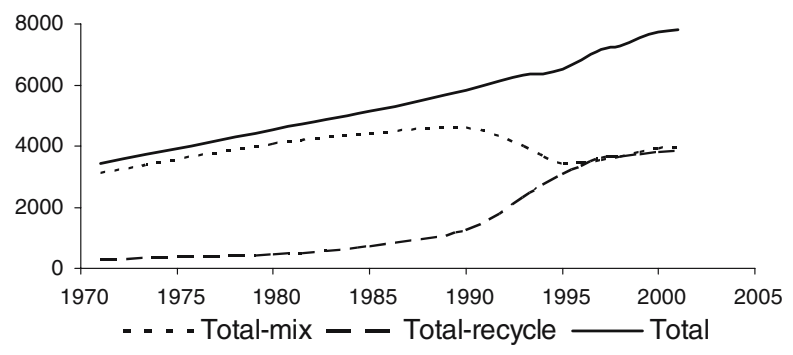

waste such as paper or glass, however, households are typically required to separate part of their waste into homogeneous streams. Recycling programs introduced in many countries typically aim to induce households to separate different types of waste and, by implication, to reduce its amount in the overall mixed waste stream. To illustrate, Fig. 1 clearly shows the remarkable rise in recycled waste streams from municipal waste in the Netherlands since 1971: from less than $9 \%$ in 1971 to over $50 \%$ in $2002 .{ }^{1}$ In absolute terms, the amount of mixed waste peaked at an all-time high of 4,600 million tons in 1990 and decreased to a low of 3,432 million tons in 1995. This 'crowding-in' effect of several homogeneous waste streams is clearly demonstrated in Fig. 2, which shows the development of the three major waste streams responsible for the rise in recycling volume in the Netherlands, i.e. paper, glass and organic waste. Paper recycling rates have doubled since 1971, but in particular the introduction of glass recycling around 1980 and the separate collection of organic waste at the beginning of the 1990s have reduced the amount of waste in the trash bin.

Separating waste into homogeneous streams requires a lot of effort that people are willing to expend only up to some level (Ackerman 1997; Huhtala 1999; Aadland and Caplan 2003; Beatty et al. 2006). Again, the Netherlands is illustrative here. As recycling is not subsidized, separation effort basically goes unpaid in this country. Nevertheless, the comprehensive recycling infrastructure for waste paper, glass and organic waste built by the Dutch government has contributed to the high recycling rates shown in Fig. 2. After an initial strong positive effect of the introduction of this infrastructure, further increases of recycling rates are typically more difficult. Indeed, rates for paper and organic waste have been decreasing slightly since 1997 (see AOO 2004). For instance, the recycling rate for organic waste has dropped - on average-from $53.7 \%$ of all organic waste in 1997 to $49.6 \%$ in 2003. This is indicative of the fact that people are becoming less inclined to separate their waste stream at home. The decline in recycling rates is even masked by the fact that an increasing number of Dutch municipalities have introduced unit-based pricing systems to stimulate recycling since 1997. These municipalities, which make up 17\% of the Dutch population, have seen recycling rates going up by 20 percentage points since (Dijkgraaf and Gradus 2004). Supplementary evidence for the important role of effort in relation to the level of recycling from an entirely different perspective is given by the study of Jenkins et al. (2003). They show that curbside recycling programs have a bigger effect on behavior than drop-off programs: the probability that the average household recycles over 95\% increases by approximately $20 \%$ for a curbside program compared with a drop-off program. ${ }^{2}$

\footnotetext{
${ }^{1}$ Results of physical monitoring of the composition of mixed household waste in the Netherlands are available since 1971. However, in the early years, monitoring was done at 5-year intervals. Since 1993, figures have been updated on a yearly basis (see AOO, 2004).

2 This is consistent with the general picture emerging from Fig. 2. In the Netherlands, recycled organic waste is collected by a curbside program, whereas bottles and paper are collected by a drop-off program.
} 


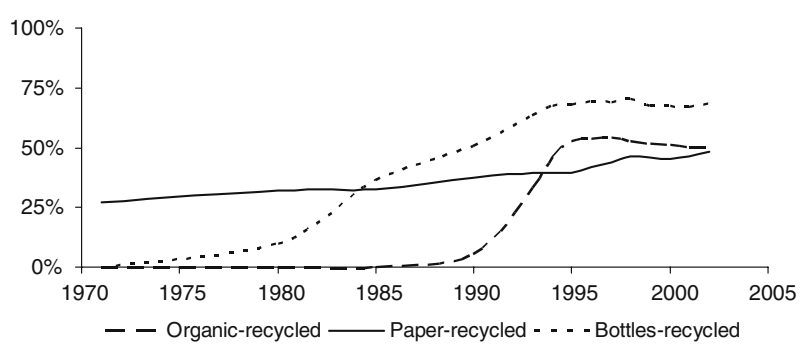

Fig. 2 Recycling as a percentage of the total amount of waste in that category in the Netherlands

In this paper, we study household waste management in a world where households have to exert effort to separate specific waste streams from their overall mix of heterogeneous waste at home in the context of a general equilibrium model. In our model, the household decides whether to keep a given type of waste separate, and thus create a homogeneous waste stream, or to throw the same unit into the trash bin, i.e. mix this unit with other types of waste. As a typical example consider a household that wants to get rid of a piece of paper. This piece could be hold separate in a box that only contains paper, or, alternatively, could be thrown in the trash bin where it is mixed with other types of waste. Holding the piece separate is likely to require more effort as one has to take care of an additional waste bin including (usually) bringing its content to a drop-off point for collection. Accordingly, our model recognizes that waste is heterogeneous in two dimensions: (i) waste may be of different types, such as paper, glass and plastics; (ii) waste of a given type (such as paper) may be part of either a separate homogeneous waste stream (like paper to be recycled) or part of the mixed waste stream in the trash bin. We will refer to the latter stream as 'the mix'. The 'location' of the waste stream has important implications for its recyclability. Throughout the paper we assume that only homogeneous waste streams, i.e. waste streams not in the trash bin, can be used for recycling. ${ }^{3}$ Recycling in our model is typically assumed to take place within firms who first collect the separated waste streams from households and then use these homogeneous waste streams as material inputs in their production process again. This assumption reflects the pattern of waste recycling from municipal waste in many OECD countries (see Porter 2002). The paper and glass industry, for instance, take a substantial part of their inputs from homogeneous waste streams collected from households or at specific locations where households drop off their separated waste.

Using this basic architecture of material waste flows in the economy, we study optimal waste policy when households have to exert separation effort to produce homogeneous waste streams suitable for recycling, whereas throwing waste into the trash bin (mixing) is costless in terms of effort. Thus we endogenize what we call the mixing decision. In our model households can avoid separation effort by throwing waste into the trash bin. They may choose from a menu of options that vary from separating all waste, at one extreme, to combining all streams in one mix, at the other. Essentially the model combines and generalizes previous work of Fullerton and Kinnaman (1995) and Choe and Fraser (1999). When households' waste reduction effort is significant Choe and Fraser (1999) argue that the government lacks

\footnotetext{
3 One might allow for the separation of waste streams after they are mixed. In that case, however, the recycled material is usually of lower quality and the firm that collects the waste has to invest in (costly) specific equipment to enable mixed waste to be separated into homogeneous streams. It would be interesting to consider a cost-benefit analysis comparing savings on recycling effort by households if they can simply mix their waste and recycling is applied after collection on the one hand and the loss in quality and productivity of such waste types on the other hand.
} 
an instrument to provide optimal incentives for both waste reduction effort and legal waste disposal because effort is unobservable. Interestingly, in our model households' waste reduction effort, while still being not observable itself, can be 'priced' through recyclable or reusable waste. By subsidizing recycled waste the government has an additional instrument to provide proper incentives to steer waste streams without the need of a second best monitoring policy on illegal dumping. Essentially we reproduce the earlier result of Fullerton and Kinnaman (1995) that a deposit-refund system is a first-best policy option for the government even if one allows for household separating effort. In addition our model shows that the composition of waste streams depends on how much effort households are willing to spend on separating different types of waste. Hence, (avoiding) separation effort is an important element in the trade-off between recycling on the one hand and landfilling (incineration) or illegal dumping on the other hand. ${ }^{4}$ Accordingly our results provide guidance to answer one of the more natural questions to ask in practice, that is how much sorting to demand from households (Porter 2002, p. 167).

Our analysis demonstrates that the optimal level of the deposit-refund scheme for the different types of waste depends on the environmental cost structure of legal versus illegal dumping as has been originally shown by Fullerton and Kinnaman (1995). The differences from earlier results are that the levels of the deposits and refunds now crucially depend on the level of mixed dumping in the social optimum and that the government may like to steer the composition of the mix in order to alleviate the detrimental effect of dumping. We consider two important cases. First, if mixed dumping for any imaginable composition is considered suboptimal - for example, because the mix contains hazardous waste - the levels of the taxes and subsidies on all types of waste are determined by the externality associated with the most harmful type of waste. ${ }^{5}$ Second, if mixed dumping is socially optimal, the government's first-best policy rule follows the deposit-refund system where the rate of taxation is based on the volume-weighted average damage of the mix plus a 'composition tax'. The latter varies by the type of waste and is used by the government to change the composition of the mix towards a more environmentally friendly composition in order to reduce the impact of dumping the mix.

Note that another strand of literature has focused on green design and the explicit link between the decisions of firms to choose a given (material) composition of their products and the 'downstream' incentives for households to reduce their overall level of waste (Fullerton and Wu 1998; Calcott and Walls 2000; Eichner and Pethig 2001, 2003). These studies focus on optimizing the recyclability of products by changing their material composition or design. For instance, by taxing products in relation to their specific waste content, producers get an incentive to change the composition of their product. In contrast, our study focuses on the entirely different question of how to obtain homogeneous waste streams suitable for recycling when this requires separation effort from households and the recycling itself, i.e. the re-use of the waste stream, is not done at home.

Our paper is organized as follows. In Sect. 2, we introduce the option of mixing waste streams in a general equilibrium model of household waste behavior allowing for a vector of

\footnotetext{
4 We reserve the label dumping for illegal dumping only in this paper. Furthermore, we use landfilling to represent legal 'dumping'.

5 Fullerton and Wolverton (2000, p. 241) also hint at this result when discussing potential generalizations of the deposit-refund system. They reason, in the context of firms producing multiple externalities, that 'the output tax has to be based on damages of the worst pollutant (and) the deposit would (then) be fully returned on all clean inputs and partially on other pollutants (at a rate equal to the difference in damages).' In our case, both the output tax and all refunds are based on the damages of the worst pollutant.
} 
consumption goods as well as effort. Next, Sect. 3 evaluates optimal policy in more detail, and Sect. 4 discusses limitations, extensions and policy implications of our approach.

\section{Sorting and mixing}

In this section, we allow households to keep waste streams separate and to mix different types of waste. As noted in the introduction, waste such as glass or organic waste may either be separated (for recycling purposes) or be thrown away into the general waste bin. Accordingly, households typically face two interlinked decisions. The first decision is whether or not to put waste in the trash bin. By throwing their waste into the trash bin, households save on effort, because separating waste streams is more costly. The second decision is about the actual disposal of the waste, i.e. waste can be recycled, landfilled or illegally dumped. For simplicity, we assume in this paper that recycling of mixed waste is not possible or too costly, because we like to focus on the effect of separating effort at the household level.

We restrict the analysis to a single jurisdiction with $n$ identical individuals or households. Each household buys a (column) vector consumption good $\boldsymbol{c}$ with $\boldsymbol{c} \equiv\left(c_{1}, c_{2}, \ldots, c_{N}\right)^{\prime}$. We further assume that consumption of good $c_{i}$ generates its own type of waste. The waste generation process can be described by

$$
w=\Psi c
$$

where $\Psi$ is a diagonal matrix with elements $\psi_{i}$ on the diagonal and the column vector $\boldsymbol{w}$ with $\boldsymbol{w} \equiv\left(w_{1}, w_{2}, \ldots, w_{N}\right)^{\prime}$ represents all waste produced by the household. Typically the rate $\psi_{i}$ captures the waste intensity of a particular good, i.e. the amount of waste associated with the consumption of good $i .^{6}$

We allow for three disposal options for separated waste. First, we denote separate waste streams available for reuse in production, like paper, glass and plastics, by the column vector $\boldsymbol{r}$ with $\boldsymbol{r} \equiv\left(r_{1}, r_{2}, \ldots, r_{N}\right)^{\prime}$. Second, the separate waste streams that are finally landfilled are described by the column vector $\boldsymbol{g}$, with $\boldsymbol{g} \equiv\left(g_{1}, g_{2}, \ldots, g_{N}\right)^{\prime}$. Third, illegal dumped separate waste streams are denoted $\boldsymbol{b}$, with $\boldsymbol{b} \equiv\left(b_{1}, b_{2}, \ldots, b_{N}\right)^{\prime}$. The total amount of separate wasted is thus equal to $\boldsymbol{r}+\boldsymbol{g}+\boldsymbol{b}$. In addition, the household has the option to put the waste in trash bin. This mixed waste stream is labelled $\boldsymbol{m}$ with $\boldsymbol{m} \equiv\left(m_{1}, m_{2}, \ldots, m_{N}\right)^{\prime}$. This column vector denotes the composition of the waste in the trash bin (the mix). Accordingly, waste disposal by households in our economy can be described by the following equation:

$$
w=r+g+b+m
$$

Finally, we allow two disposal options for mixed waste in the trash bin: landfilling or dumping. The total amount of mixed waste is given by the scalar $\iota \boldsymbol{m}$, i.e. the sum of all its different components, where $\iota$ is the row vector of ones. The fraction of the mix that is dumped is given by $\alpha$. Hence, the amount of waste that is landfilled from the trash bin labeled mixed landfilling - is equal to $g_{0}=(1-\alpha) \iota \boldsymbol{m}$. $^{7}$

Accordingly, the total amount of waste landfilled or dumped illegally in our model may come from two 'sources'. The first source is waste streams that have been kept separate from

\footnotetext{
6 Note that our vector notation also allows for differences in quality of apparently 'homogeneous' waste streams such as glass or paper.

7 A subscript of zero denotes mixed streams of waste; subscripts larger than zero denote separate streams of waste. Thus $m_{i}$ is the amount of waste $i$ thrown into the trash bin, $\boldsymbol{m}$ represents the composition of (mixed) waste in the trash bin and $\iota m$ is the total amount of mixed waste (the mix).
} 
Fig. 3 Architecture of household waste streams

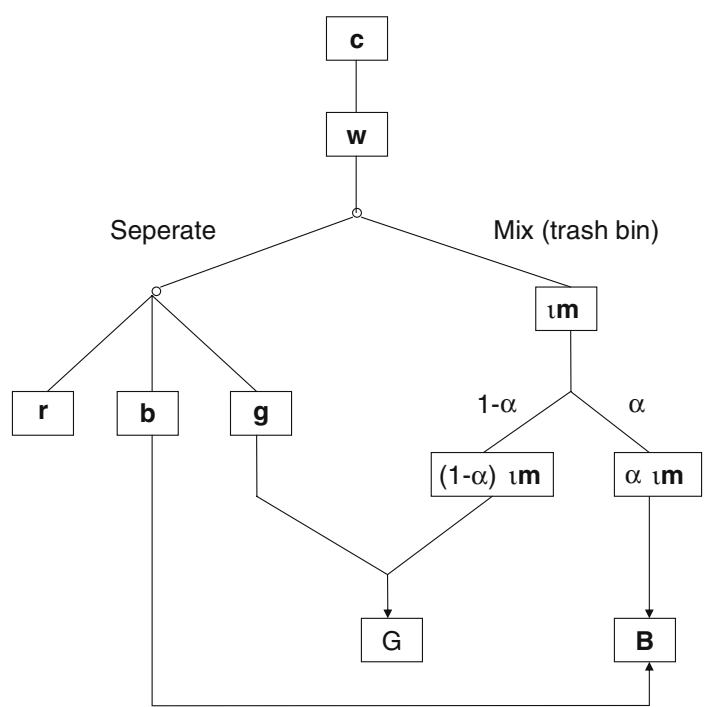

the beginning ( $\boldsymbol{g}$ and $\boldsymbol{b}$ ). For instance, the trash bin may not be suitable for all types of waste, either because of size, weight or smell (e.g. old mattresses, wood, rotten leaves, brick stones, etc.), and such waste streams are likely to be kept separate until disposal. The second source is the mixed waste stream, part of which may be landfilled and part of which may be dumped. We summarize the basic architecture of our model in Fig. 3. Thus our model allows for the same type of waste to appear in both separate and mixed waste streams even though the disposal option may be equal. For example, plastics may both be landfilled as a separate and as a mixed stream.

The total amount of waste landfilled, $G$, is computed in three steps. First, we compute the total amount of waste that has been kept separate, but is ultimately landfilled by a single household, $\mathbf{g}$. Second, we add the fraction of the mixed waste going to the landfill to find the overall supply of landfilled waste for a single household, $g_{0}$. Finally, we aggregate over all households supplying waste for landfilling. Hence,

$$
G=n \iota g+n g_{0}=n \iota g+n(1-\alpha) \iota m
$$

We assume that the environmental effects of landfilled waste depend on its overall level $G$, but not on its composition: due to the asymmetry in information about the type of waste, landfills are typically ignorant of the types of waste included in the overall mix at their sites. Moreover, different compositions of waste streams are likely to show up over time and a large part of these waste streams are mixed. Therefore landfills face some randomness as to what types of wastes are included in the mix and they have to hedge against the risk of leaking from the overall (mixed) waste stream. Indeed, modern landfills are designed in such a way that ambient quality of the environment is guaranteed by securing against leakage of the worst type of waste (Dijkgraaf and Vollebergh 2004).

The total amount of waste that is illegally dumped, $\boldsymbol{B}$, can be determined in a similar procedure. It is given by

$$
\boldsymbol{B}=n \boldsymbol{b}+n \alpha \boldsymbol{m}
$$

where the column vector $\boldsymbol{B} \equiv\left(B_{1}, B_{2}, \ldots, B_{i}, \ldots, B_{N}\right)^{\prime}$. The external effect of dumping, however, is not determined by the total amount dumped, but by the separate amount dumped 
of each type of waste. ${ }^{8}$ We assume that there are no interaction effects ( 'cocktails') associated with dumping waste.

Households have to spend effort on handling their waste before it is disposed which is captured by the overall (column) vector of effort $\boldsymbol{e} \equiv\left(e_{1}, e_{2}, \ldots, e_{N}\right)^{\prime}$. We assume effort is linear and separable for each of the waste components distinguished before (see equation (2)) according to

$$
\boldsymbol{e}=\Omega_{r} \boldsymbol{r}+\Omega_{g} \boldsymbol{g}+\Omega_{b} \boldsymbol{b}+\Omega_{m} \alpha \boldsymbol{m}
$$

with $\Omega_{r}, \Omega_{g}, \Omega_{b}$ and $\Omega_{m}$ being diagonal matrices with elements $\omega_{j i}, j \in[r, g, b, m]$. Here, $\omega_{j i}$, denotes the effort intensity for disposal option $j$ and waste type $i$. Accordingly our model allows for differences in effort in the handling of waste by households. The effort intensities capture the effort needed to both separate and dump waste. First, separation effort is relevant only for waste streams that are separated, i.e. $\boldsymbol{r}, \boldsymbol{g}$ and $\boldsymbol{b}$, and is zero for waste put into the trash bin, $\boldsymbol{m}$. Second, the household may expend effort for dumping waste illegally, both separate, $\boldsymbol{b}$, and mixed, $\alpha \boldsymbol{m}$. Additional resources are also required for recycling and landfilling but they are typically assumed not to be born by the household itself but by the recycling or landfilling firm. Accordingly, dumping a separate waste stream requires probably the highest levels of household effort as effort is required for both separation and getting rid of the waste (e.g. driving to a dumping location), whereas the landfilling of mixed waste requires no effort on behalf of the household.

Households derive utility from household consumption, $\boldsymbol{c}$, the total amount of waste landfilled, $G$, and a (row) vector of different types of waste disposed off illegally, $\boldsymbol{B}$. The utility function reads:

$$
U=U[\boldsymbol{c}, \boldsymbol{e}, G, \boldsymbol{B}]
$$

The marginal utility of consumption, effort, landfilling and dumping are given by $\boldsymbol{U}_{\boldsymbol{c}}$, $\boldsymbol{U}_{\boldsymbol{e}}, U_{G}$ and $\boldsymbol{U}_{\boldsymbol{B}}$, respectively. Here $\boldsymbol{U}_{\boldsymbol{c}}, \boldsymbol{U}_{\boldsymbol{e}}$ and $\boldsymbol{U}_{\boldsymbol{B}}$ are column vectors. Single elements are denoted by $U_{j i}$ with $j \in[c, e, B]$. We assume $\boldsymbol{U}_{\boldsymbol{c}}>0, \boldsymbol{U}_{\boldsymbol{e}}, U_{G}, \boldsymbol{U}_{\boldsymbol{B}}<0 .{ }^{9}$ Garbage at the landfill causes negative utility mainly due to aesthetic and health risk associated with leakage hazards, but this utility loss is likely to be smaller than the loss from illegal dumping. Therefore we assume in addition that $U_{B i} \leq U_{G}$. Finally, the social cost from dumping waste may differ according to the type of waste. For instance, the effect of dumping batteries is much more severe than the effect of dumping organic waste. To capture such differences we make the convention that $U_{B 1} \leq U_{B 2} \leq \cdots \leq U_{B N}$ : more hazardous wastes have a lower index. ${ }^{10}$

Production is fairly straightforward. To focus attention entirely on disposal behavior of households, we simply assume output produced according to a constant-returns-to-scale production function according to

$$
\boldsymbol{c}=F\left(\boldsymbol{k}_{\boldsymbol{c}}, \boldsymbol{r}\right) \equiv\left(f^{1}\left(k_{c 1}, r_{1}\right), f^{2}\left(k_{c 2}, r_{2}\right), \ldots, f^{N}\left(k_{c N}, r_{N}\right)\right)^{\prime}
$$

with input of resources $\boldsymbol{k}_{\boldsymbol{c}}=\left(k_{c 1}, k_{c 2}, \ldots, k_{c N}\right)^{\prime}$ and recycled materials $\boldsymbol{r}$ from used consumption goods. We ignore peculiarities of the recycling process itself and simply as-

\footnotetext{
8 This explains the absence of $\iota$ in (4) compared to (3).

9 Note that we do assume that households only derive negative utility from recycling efforts. This is not to deny that households might also gain utility from the process of recycling, but we belief that there will be always some point beyond which households consider marginal recycling effort to become negative.

10 As pointed out by a referee this assumption is likely to hold only locally and not on the entire domain of $\mathrm{U}$. Indeed, it is unlikely that the marginal disutility of one waste stream is always larger than another stream irrespective of the dumped level of this stream. The same holds for differences between the marginal disutility of landfilling $\left(U_{B i}\right)$ and dumping $\left(U_{G}\right)$.
} 
sume that reuse is costless and smooth. ${ }^{11}$ For simplicity, we assume that the production of consumption good $i$ requires its own technology and only uses its 'own' recycled material, or $c_{i}=f^{i}\left(k_{c i}, r_{i}\right)$. We assume that $f_{k c i}^{i}>0$ and $f_{k c i, k c i}^{i} \leq 0$ by CRTS.

Garbage collection and processing at the landfill requires one input, $k_{g i}$, and uses a constant-returns-to-scale production function which is identical for each type of garbage.

$$
g_{i}=\gamma k_{g i} \Leftrightarrow \boldsymbol{g}=\gamma \boldsymbol{k}_{\boldsymbol{g}}
$$

The mixed landfilling technology is identical to the technology for separate landfilling:

$$
g_{0}=\gamma k_{g 0}
$$

Recall that no such technology is involved in dumping as we take it that our effort function already captures this. ${ }^{12}$

Finally, the model is closed by the resource constraint

$$
k=\boldsymbol{\iota} \boldsymbol{k}_{\boldsymbol{c}}+\boldsymbol{\iota} \boldsymbol{k}_{\boldsymbol{g}}+k_{g 0}
$$

where $k$ is a fixed total resource such as capital or labor.

The social planner's problem is to maximize the utility of the representative household, Eq. 6, subject to the constraints (1), (2), (3), (4), (5), (7), (8), (9), and (10), with respect to the variables $\boldsymbol{r}, \boldsymbol{g}, \boldsymbol{b}$ and $\boldsymbol{k}_{\boldsymbol{c}}, \boldsymbol{m}$ and $\alpha$. The Lagrangian explicitly accounts for the effect of mixing on consumption and effort as well as for the external effects of mixed landfilling or mixed dumping, and reads

$$
\begin{aligned}
\mathcal{L}= & U\left[\Psi^{-1}(\boldsymbol{r}+\boldsymbol{g}+\boldsymbol{b}+\boldsymbol{m}), \Omega_{r} \boldsymbol{r}+\Omega_{g} \boldsymbol{g}+\Omega_{b} \boldsymbol{b}+\Omega_{m} \alpha \boldsymbol{m},\right. \\
& n \boldsymbol{\iota} \boldsymbol{g}+n(1-\alpha) \iota \boldsymbol{m}, n \boldsymbol{b}+n \alpha \boldsymbol{m}]+\boldsymbol{\delta}\left[F\left(\boldsymbol{k}_{\boldsymbol{c}}, \boldsymbol{r}\right)-\Psi^{-1}(\boldsymbol{r}+\boldsymbol{g}+\boldsymbol{b}+\boldsymbol{m})\right] \\
& +\mu\left[k-\boldsymbol{\iota} \boldsymbol{k}_{\boldsymbol{c}}-\boldsymbol{\imath} \boldsymbol{g} / \gamma-(1-\alpha) \iota \boldsymbol{m} / \gamma\right]
\end{aligned}
$$

Note that this optimization recognizes that every individual imposes costs on others through landfilling and illegal dumping. Differentiation of the above Lagrangian and substituting out the first-order conditions for $\boldsymbol{k}_{\boldsymbol{c}}$ yields the following first-order (Kuhn-Tucker) conditions: ${ }^{13}$

$$
\begin{aligned}
& r: \quad \frac{U_{c i}}{\psi_{i}}+\omega_{r i} U_{e i}=\delta_{i}\left(\frac{1}{\psi_{i}}-f_{r i}^{i}\right) \\
& g: \quad \frac{U_{c i}}{\psi_{i}}+\omega_{g i} U_{e i}+n U_{G} \leq \delta_{i}\left(\frac{1}{\psi_{i}}+f_{k c i}^{i} / \gamma\right) \\
& \boldsymbol{b}: \quad \frac{U_{c i}}{\psi_{i}}+\omega_{b i} U_{e i}+n U_{B i} \leq \delta_{i} \frac{1}{\psi_{i}} \\
& \boldsymbol{m}: \frac{U_{c i}}{\psi_{i}}+\alpha \omega_{m i} U_{e i}+n(1-\alpha) U_{G}+n \alpha U_{B i}=\delta_{i}\left(\frac{1}{\psi_{i}}+(1-\alpha) f_{k c i}^{i} / \gamma\right) \\
& \alpha: \quad \Omega_{m} \boldsymbol{m} \boldsymbol{U}_{\boldsymbol{e}}-n \boldsymbol{\imath} \boldsymbol{m} U_{G}+n \boldsymbol{m} \boldsymbol{U}_{\boldsymbol{B}} \leq-\delta_{i} f_{k c i}^{i} \iota \boldsymbol{m} / \gamma
\end{aligned}
$$

\footnotetext{
11 Remember our focus is on mixing behavior of households and not on firms' ability to change the material composition of given products as studied in the green design literature. See Fullerton and Wu (1998) and Eichner and Pethig (2001).

12 So we do not follow Fullerton and Kinnaman (1995) who include a illegal dumping technology in terms of the resource, $k$. None of our results are affected in any fundamental respect, however, if we would distinguish explicitly between separation effort and (additional) resources that the household has to spend in order to dump their waste illegally themselves (see Aalbers and Vollebergh 2005).
}

13 Note that Eqs. 12a-d all hold for $i=1, \ldots, N$. 
We assume second-order conditions hold and $\alpha<1$. The first three equations just indicate that marginal utility made possible through any additional $\boldsymbol{r}, \boldsymbol{g}$ or $\boldsymbol{b}$ must equal marginal social cost. They closely follow the earlier results obtained by Fullerton and Kinnaman (1995) with only inequality instead of equality signs in Eqs. 12b,c. The major difference is that effort now enters marginal cost for all disposal options. The first additional equation (12d) guides the choice as to how much mixing is optimal from social planners perspective. The social planner weighs the additional utility of consumption and disutility of effort (because of mixed dumping) of an additional unit of waste against an increase in the resources necessary for proper waste disposal and the external costs of mixed landfilling and dumping.

The second additional equation (12e) shows how much of the available mixed waste should be dumped (the fraction $\alpha$ ). Clearly, a larger fraction of mixed waste being dumped saves the resources necessary for landfilling the same amount of waste, but requires more effort for dumping. The overall balance also depends on the environmental externalities of landfilling that are saved and the additional externalities due to dumping.

\section{Modified deposit-refund systems}

This section explores optimal waste policy of the government in a world where households can mix their waste and optimally choose their level of (separation) effort. Given the rather complicated structure of our model we, first of all, derive the conditions for a private market equilibrium where the government could use consumption, recycling and landfill taxes to steer household behavior in the socially preferable direction. Next we explore the optimal policy of the government when mixing is not possible to better understand the differences of our model compared to the earlier contributions in the literature. Then we continue with two cases where mixing is possible. The first case discusses mixing when all dumping is considered suboptimal and the second case allows for mixed dumping only. (Optimal) dumping of separate waste streams in equilibrium is not considered in this section.

\subsection{Private market equilibrium}

For the case of private markets, producers of consumption goods receive a unit price $(=1)$ for selling $c$ and receive the price, $p_{\boldsymbol{r}}$, paid by consumers for recycling good $\boldsymbol{r}$ which can be positive or negative. ${ }^{14}$ They maximize profits $\boldsymbol{c}+\boldsymbol{p}_{\boldsymbol{r}} \boldsymbol{r}-p_{k} \boldsymbol{\iota} \boldsymbol{k}_{\boldsymbol{c}}$ under perfect competition with constant returns to scale. Hence, $p_{k}=f_{k c i}^{i}$ and $p_{r i}=-f_{r i}^{i}$ for $i=1, \ldots, N$. Producers of landfilling services maximize $p_{g 0} g_{0}+\boldsymbol{p}_{\boldsymbol{g}} \boldsymbol{g}-p_{k} k_{g 0}-p_{k} \boldsymbol{\iota} \boldsymbol{k}_{\boldsymbol{g}}$, so $p_{g i}=p_{k} / \gamma$ for $i=0, \ldots, N$. Households maximize utility in Eq. 6 subject to (1), (2), (5), $g_{0}=(1-\alpha) \iota m$, and the budget constraint

$$
p_{k} k=\left(\mathbf{1}+\boldsymbol{t}_{\boldsymbol{c}}\right) \boldsymbol{c}+\left(\boldsymbol{p}_{\boldsymbol{r}}+\boldsymbol{t}_{\boldsymbol{r}}\right) \boldsymbol{r}+\left(\boldsymbol{p}_{\boldsymbol{g}}+\boldsymbol{t}_{\boldsymbol{g}}\right) \boldsymbol{g}+\left(p_{g 0}+t_{g 0}\right) g_{0}
$$

where $p_{k}$ is the price earned on resources, the price of consumption is equal to 1 since $c$ is the numeraire, $\boldsymbol{p}_{\boldsymbol{r}}$ is the price paid or received by the consumer for recycling, $\boldsymbol{p}_{\boldsymbol{g}}$ is the price paid for garbage collection, and $\boldsymbol{t}_{\boldsymbol{c}}, \boldsymbol{t}_{\boldsymbol{r}}$ and $\boldsymbol{t}_{\boldsymbol{g}}$ are the per-unit taxes (or subsidies) on respectively consumption, recycling and landfilling. Note that — apart from effort — illegal dumping is costless for the consumer. This reflects explicitly the assumption that this activity is untaxable

\footnotetext{
14 The actual consumer price for recycling depends on two factors. First, the consumer may be prepared to pay the firm for the disposal of (part of) the waste as long as it decreases the costs of landfilling for the consumer and the effort intensity of recycling is not too high. Second, the firm is prepared to pay the consumer up to the marginal value of the waste in the production of the consumer good.
} 
which causes a fundamental asymmetry in tax instruments available to the government. The government may use a tax on mixed landfilling, $t_{g 0}$, but has no direct instrument to control the level of mixed dumping.

The first-order conditions for private markets are: ${ }^{15}$

$$
\begin{aligned}
& \boldsymbol{r}: \frac{U_{c i}}{\psi_{i}}+\omega_{r i} U_{e i}=\lambda\left(\frac{1+t_{c i}}{\psi_{i}}-f_{r i}^{i}+t_{r i}\right) \\
& \boldsymbol{g}: \frac{U_{c i}}{\psi_{i}}+\omega_{g i} U_{e i} \leq \lambda\left(\frac{1+t_{c i}}{\psi_{i}}+f_{k c i}^{i} / \gamma+t_{g i}\right) \\
& \boldsymbol{b}: \frac{U_{c i}}{\psi_{i}}+\omega_{b i} U_{e i} \leq \lambda\left(\frac{1+t_{c i}}{\psi_{i}}\right) \\
& \boldsymbol{m}: \frac{U_{c i}}{\psi_{i}}+\alpha \omega_{m i} U_{e i}=\lambda\left(\frac{1+t_{c i}}{\psi_{i}}+(1-\alpha) f_{k c i}^{i} / \gamma+t_{g 0}(1-\alpha)\right) \\
& \alpha: \quad \Omega_{m} \boldsymbol{m} \boldsymbol{U}_{\boldsymbol{e}} \leq-\lambda\left(f_{k c i}^{i} / \gamma+t_{g 0}\right) \iota \boldsymbol{m}
\end{aligned}
$$

where we have replaced the prices $\left(p_{k}, p_{g i}, p_{g 0}\right.$ and $\left.p_{r i}\right)$ with the marginal products $\left(f_{k c i}^{i}\right.$, $f_{k c i}^{i} / \gamma, f_{k c i}^{i} / \gamma$ and $-f_{r i}^{i}$, and $\lambda$ is the marginal utility of income. These first-order conditions demonstrate the matching of private marginal utility (net of effort) with the cost of each activity.

We are now in the position to discuss different policy options that can attain the first-best allocation of resources. Equations 14a-e are the Kuhn-Tucker conditions for the household problem. Notice that the optimal solution to $14 \mathrm{a}-\mathrm{e}$ may be a corner solution. However, not each of these solutions is equally interesting or viable. While we explicitly consider corner solutions for landfilling, $\boldsymbol{g}^{*}$, and illegal dumping, $\alpha^{*}$ and $\boldsymbol{b}^{*}$, we assume interior solutions for recycling, $\boldsymbol{r}^{*}>0$. This assumption may appear rather strong because it seems hardly viable and even sometimes impossible to recycle every waste stream in practice. However, we do not discuss this case in more detail because the obvious (first best) policy is not to use an instrument to stimulate recycling for these non-recyclable types of waste. This could be easily understood with our model. Consider the case where some waste streams are not recycled in equilibrium, i.e. $r_{i}^{*}=0$ for some $i$. This case may arise due to a variety of reasons. First of all, consumers may derive a strong disulitity $\left(\omega_{r i} \ll 0\right)$ from recycling certain types of waste, for instance due to some properties of the waste stream (e.g. smell) or cumbersome handling of the waste (e.g. lack of space for temporary storage of the waste). ${ }^{16}$ Second, waste may not be very or even non-productive in the production process $\left(f_{r i}^{i} \ll 0\right)$, for instance due to technical limitations. Comparing Eqs. 12a and 14a shows that any $t_{r i}>-t_{c i} / \psi_{i}$ will result in $r_{i}^{*}=0$. As $t_{c i}$ is positive, simply putting $t_{r i}$ equal to zero will suffice in order to implement the first best in this case.

\subsection{No mixing with dumping}

For sake of reference we start with the case without mixing. In the case without mixing, i.e. $\boldsymbol{m}^{*}=0$, there is only separate dumping and separate landfilling as in Fullerton and Kinnaman (1995). Hence, no choice has to be made as to how much of the available mixed waste should be dumped, i.e. $\alpha^{*}=0$ in this case and the instrument targeting mixed landfilling, $t_{g 0}$, has no meaning. Assuming an interior solution exist for this case, the optimization problem reduces

\footnotetext{
15 Again remember that Eqs. 14a-d all hold for $i=1, \ldots, N$.

16 In Sect. 4 we discuss a number of factors influencing the rate of recycling observed in practice.
} 
to a much simpler system with first-order conditions $(14 \mathrm{a}-\mathrm{c})$ with equality signs instead of the inequality signs in (14b) and (14c). With all tax rates equal to zero, it is clear that no matching exists for the external cost of both landfilling, $n U_{G}$, and illegal dumping, $n U_{B i}$, in Eqs. 12b,c respectively. To compensate for those costs, the social planner has to implement a set of Pigouvian taxes such that the social marginal cost is equal to the social marginal benefit for each disposal method. Comparing the foc's of the social planner with those of the household suggests that we can use $\delta_{i}=\lambda$ to find the following set of optimizing tax rates:

$$
\begin{aligned}
t_{c i}^{*} & =-n U_{B i} \psi_{i} / \lambda, \quad i=1, \ldots, N \\
t_{r i}^{*} & =n U_{B i} / \lambda, \quad i=1, \ldots, N \\
t_{g i}^{*} & =n\left(U_{B i}-U_{G}\right) / \lambda, \quad i=1, \ldots, N
\end{aligned}
$$

with these Pigouvian rates, private behavior in Eqs. $14 \mathrm{a}-\mathrm{c}$ matches the social optimum in Eqs. 12a-c. We include the result for this case in the first column of Table 1.

It is easy to see that this model produces a deposit-refund system for each separate waste stream as the first-best optimal tax system. Without illegal dumping of separate waste streams (and therefore $\boldsymbol{b}^{*}=0$ ), a simple first-best solution exist with taxes $t_{c i}=t_{r i}=0$ and $t_{g i}=-n U_{G} / \lambda$ on landfilled waste in order to compensate for the externality associated with landfilling. ${ }^{17}$ This Pigouvian tax is obviously $>0$ since $U_{G}<0$. The larger the externality and the number of people affected, the higher its rate.

With (separate) illegal dumping, however, an additional instrument is required to induce households towards its optimal level. Optimal behavior is induced by collecting $t_{c i}=$ $-n U_{B i} \psi_{i} / \lambda$ on each purchase, where the tax rises with the waste intensity, $\psi_{i}$. A rebate is obtained upon proper disposal of that item, i.e. through either recycling or landfilling (net of its external effects). This follows from comparing (14a) and (12a) to find $t_{r i}=n U_{B i} / \lambda$. Furthermore, we find $t_{g i}=n\left(U_{B i}-U_{G}\right) / \lambda$ from comparing (14b) and (12b). Thus a higher rebate is obtained for recycled waste compared to landfilled waste reflecting the environmental cost of landfilling, $n U_{G}$. Note also that the deposit refund system now explicitly accounts for differences in waste intensity of consumption goods and the deposit is higher the more waste intensive the good is. Refunds do not depend on this intensity because they are provided on units of waste, not consumption. ${ }^{18}$ Finally, note that the introduction of disutility of effort has no effect on the structure of the optimal rates in this case at all.

It is remarkable that the first best can be attained in this case as the government lacks a (direct) tax base that could be used as an instrument to attain the optimal social composition of waste disposal in general and illegal dumping in particular. Therefore it is useful to compare our model with the results obtained by Choe and Fraser (1999). They point out that a simple Pigouvian policy that uses a tax on waste collection would be suboptimal if effort by households to reduce waste through reuse or composting were significant. In that case the government lacks an instrument to simultaneously steer both waste reduction and illegal waste disposal (see also Choe and Fraser (2001)). Recycling in our model, however, is fully observable and waste reduction through reuse is part of the formal economy. ${ }^{19}$ Therefore the first-best can be reached in our model due to the subsidy on recycling, $t_{r}$. Only without this instrument the first best is no longer attainable in our model and it would appear as

17 As noted by Fullerton and Kinnaman (1995), this is just one solution out of an infinite number of solutions. The only requirement is that the net tax is zero.

18 Note that this result is similar to Fullerton and Kinnaman (1995) for their case of 'disaggregated goods and services', if $\psi_{i}=1$.

19 Figures 1 and 2 illustrate that the volume of recycled waste in the formal economy, i.e. recycling through the market, is substantial and observable. 
Table 1 Comparison of various tax schemes to achieve the first-best

\begin{tabular}{|c|c|c|}
\hline Case 1: No mixing with dumping & Case 2: Mixing without dumping & $\begin{array}{l}\text { Case 3: Mixing with mixed } \\
\text { dumping }\end{array}$ \\
\hline$t_{c i}^{*}=-n \psi_{i} U_{B i} / \lambda$ & $t_{c i}^{*}=-n \psi_{i}\left(U_{G} / \lambda-t_{g 0}^{*}\right)>$ & $t_{c i}^{*}=-n \psi_{i}\left((1-\alpha) U_{B w}\right.$ \\
\hline $\begin{array}{l}t_{r i}^{*}=n U_{B i} / \lambda \\
t_{g i}^{*}=n\left(U_{B i}-U_{G}\right) / \lambda\end{array}$ & $\begin{array}{l}t_{r i}^{*}=-t_{c i}^{*} / \psi_{i}<n U_{B 1} / \lambda \\
t_{g i}^{*}=0\end{array}$ & $\begin{aligned} t_{r i}^{*}= & n\left((1-\alpha) U_{B w}+\alpha U_{B i}\right) / \lambda \\
t_{g i}^{*}= & n\left((1-\alpha) U_{B w}+\alpha U_{B i}\right. \\
& \left.-U_{G}\right) / \lambda\end{aligned}$ \\
\hline$t_{g 0}^{*}=0$ & $t_{g 0}^{*}<n\left(U_{B 1}-U_{G}\right) / \lambda$ & $t_{g 0}^{*}=n\left(U_{B w}-U_{G}\right) / \lambda$ \\
\hline
\end{tabular}

Note $1: t_{c i}^{*}, t_{r i}^{*}, t_{g i}^{*}$ and $t_{g 0}^{*}$ are, respectively, tax rates on consumption, recycling, landfilling separate waste and landfilling mixed waste. $U_{B i}$ and $U_{G}$ are the (negative) externalities of each illegally dumped waste stream and landfilling respectively, $U_{B 1}$ is the externality of the waste stream with the worst profile (cases 2 and 3 ) and $U_{B w}$ is the environmental effect of dumping the mix in which the waste stream is contained (case 3 only). $\alpha$ is the fraction of the mix that is dumped, $\lambda$ is the private marginal utility of income, $n$ is the number of individuals and $i$ is the index for each separate waste stream

Note $2: t_{g i}^{*}=0$ if $g_{i}^{*}=0$

if introducing effort destroys the benevolent effect of the deposit-refund system. A similar conclusion has been reached by Shinkuma (2003) as well, who also demonstrated that the first-best can be achieved even if households have to exert significant effort.

\subsection{Mixing without dumping}

To study the consequences of separation effort it is essential to allow for the possibility of mixing, i.e. $\boldsymbol{m}^{*}>0$. This implies that the same type of waste can now be 'encountered' as a homogeneous, separate waste stream or (and) as waste being part of the mixed waste in the trash bin. Accordingly, our model captures the fact that recycling rates of specific waste streams, like paper or glass, are typically below $100 \%$. In the remainder of this and the next subsection, we restrict the analysis of mixed waste to the case where it is not optimal to have dumping of separate waste streams in equilibrium, for reasons that will become clear in the last section, i.e. we assume $\boldsymbol{b}^{*}=0$. That still leaves us with two subcases, one without and one with mixed dumping in the social optimum. This section starts with the first subcase where mixed dumping is suboptimal and therefore $\alpha^{*}=0$ and leaves the other subcase to Sect. 3.4.

The optimal solution in this case is given by Equating (12a) and (12d) with (14a) and (14d) respectively. ${ }^{20}$ Again, the case where all taxes are zero is illustrative. Comparing (14d) with (12d) and substituting $\alpha=0$, we see that only (12d) would account for the external cost of landfilling. At zero taxes, there would be too much mixed waste in the private optimum.

As shown in the second column of Table 1, a modified deposit-refund system could again be used to induce private behavior of households as described in (14) to recycle enough waste to match the unique social optimum in (12). The subsidy on recycling is still equal to the tax on consumption corrected for the waste intensity of the consumption goods and can easily be derived by comparing (12a) and (14a). In contrast to the previous case without

20 By imposing $\alpha^{*}=0$, we also have $\boldsymbol{g}^{*}=0$ as part of our optimal policy. Substituting $\alpha^{*}=0$ into (12d), we get $\forall i: \frac{U_{c i}}{\psi_{i}}+n U_{G}=\delta_{i}\left(\frac{1}{\psi_{i}}+f_{k c i}^{i} / \gamma\right)$. From this, it follows by substitution that (12b) must hold with strict inequality. Hence, $g^{*}=0$. Thus, whenever mixed dumping is not optimal, mixing becomes identical to (mixed) landfilling. And as, compared to separate landfilling, mixed landfilling saves on effort, we must have that separate landfilling cannot occur in any equilibrium without mixed dumping. 
mixing, we find by comparing (12d) and (14d) that any optimal tax scheme has to satisfy $t_{c i}^{*}+t_{g 0}^{*} \psi_{i}=-n U_{G} \psi_{i} / \lambda$. Thus, the optimal tax on consumption has now to be returned to the consumer up to the external effect of landfilling $\left(-n U_{G} / \lambda\right)$ corrected for the waste intensity of consumer goods. As a consequence the tax base shifts towards mixed waste only and households obtain a refund on mixed waste that goes to the landfill which is high enough to compensate for the externality associated with landfilling. A tax on separate landfilled waste is no longer needed because it makes little sense to expend additional effort on first separating waste and then taking it to a landfill where it is mixed anyway.

Finally, we show in Appendix section A.1 that a local solution to our problem yields $t_{g 0}^{*}<n\left(U_{B 1}-U_{G}\right) / \lambda .^{21}$ Consequently, we find the (local) optimal taxes $t_{c i}^{*}>-n U_{B 1} \psi_{i} / \lambda$ and $t_{r i}^{*}=-t_{c i}^{*} / \psi_{i}<n U_{B 1} / \lambda$. Because the household must be induced not to dump at all, the refund on mixed waste should be large enough to prevent dumping in this case. Hence, both the consumption tax (corrected for its waste intensity) and the subsidies on recycling and mixed landfilling are now higher for all less detrimental wastes than in the case where households do not have the option to mix wastes: for waste of type $i$, any refund on separate landfilling larger than $n\left(U_{B i}-U_{G}\right) / \lambda$ would ensure no dumping. Since $U_{B 1} \leq \cdots \leq U_{B N}$, the refund on mixed landfilling must be larger than $n\left(U_{B 1}-U_{G}\right) / \lambda:^{22}$ the environmentally most detrimental waste now sets the minimum level of tax on consumption for each good and the subsidies on recycling and landfilling for each type of waste.

Notice that the result for the case without dumping is much simpler than the set of taxes and refunds necessary in the model with heterogeneous waste without mixing (see Fullerton and Kinnaman 1995). Not only do consumers face a more straightforward deposit-refund system (on fewer waste streams), also the government may save on administration and enforcement costs because it no longer has to organize a separate deposit-refund system for each type of waste. Consider, for instance, the case where households discard solvents, like thinner, or batteries. If the hazards of either of these streams are such that dumping them separately or in the mix should be avoided, these hazards also guide the level of the deposit-refund for all other (potential) waste streams. To guarantee that all waste is properly handled, the government has to 'hedge' against the potentially worst option. This can easily be done by setting the proper levels of the deposit-refund.

\subsection{Mixing with mixed dumping}

The next, and perhaps more interesting case allows mixing together with mixed dumping, i.e. both $\boldsymbol{m}^{*}>0$ and $\alpha^{*}>0$. Note that up to some extent, mixed dumping can be an optimal policy. This would be the case, for instance, if the environmental effects of dumping the most hazardous waste present in household waste are not too large. Indeed, 'most hazardous' is a relative concept and much depends on how hazardous particular streams are and where dumping is likely to occur. We distinguish between two subcases, one where the optimal policy of the government includes landfilling of separate waste streams and one where this policy does not include this type of landfilling.

\footnotetext{
21 This condition comes from the requirement that the taxes must satisfy not only the equality conditions, but also the inequality conditions and the assumptions with respect to the ordering of the disutility of dumping different wastes streams mentioned before (see Sect. 2). Remember that we assumed $U_{B i} \leq U_{G}$ and $U_{B h} \leq U_{B i}$ for $h<i$. Note also that we assume lump-sum recycling of potential budget surpluses (deficits) throughout this paper.

22 Because $U_{G} \leq U_{B i}$ the Pigovian 'tax' is $\leq 0$ for all types of waste.
} 


\subsubsection{Mixed dumping with separate landfilling}

We start with the most important subcase where the optimal policy of the government includes landfilling of separate waste streams, i.e. where $g^{*}>0$. The optimum in this case is given by Eqs. 12a,b,d and e. The case of zero taxes now shows that we have too little separate landfilling in the optimum because households do not want to spend the effort to separate part of the waste for separate landfilling (compare (12b) and (14b)). Consequently, there is too much mixing, which can be verified from (12d) and (14d). Finally, from (12e) and (14e), we have that there is too much dumping in the absence of taxation.

Again comparison of the foc's of the social planner and the household indicates that $\delta_{i}=\lambda$, i.e. the social marginal utility equals the private marginal utility of the resource. Next, define $U_{B w}=\boldsymbol{m} \boldsymbol{U}_{\boldsymbol{B}} / \boldsymbol{\imath} \boldsymbol{m}$ as the weighted disutility of dumping mixed waste where the weights are given by the quantity (or share) of each waste in the mix. Next, from (12e) and (14e) and using $\delta_{i}=\lambda$, we find $t_{g 0}^{*}=n\left(U_{B w}-U_{G}\right) / \lambda$ to guide the optimal level of dumping mixed waste. Since $U_{B w} \leq U_{G}$, the refund for mixed waste is still similar to the result found in the previous subsection: the more detrimental - in terms of its externality - it is to dump the mix compared with landfilling, the higher the refund on proper disposal should be. However, the subsidy on proper disposal through landfilling now rises with the disutility of dumping the mix and in this case no longer depends on the disutility of dumping the most hazardous type of waste.

Apart from guiding the optimal level of the mix being dumped, the first-best solution should also guide households as to what type of waste they should throw into the trash bin. Not surprisingly, this decision is guided by the various externalities involved in dumping a specific waste stream, either separate or mixed. Indeed, by substituting $t_{g 0}^{*}$ and comparing (12d) and (14d), we find $t_{c i}^{*}=-n \psi_{i}\left((1-\alpha) U_{B w}+\alpha U_{B i}\right) / \lambda$, which is greater than or equal to zero given $U_{B i}, U_{B w} \leq 0$. Households now pay a tax (deposit) that is a weighted average of the environmental effect of dumping the waste separately, $U_{B i}$, and the environmental effect of dumping the mix in which the waste is contained, $U_{B w}$. Again the tax is corrected for the waste intensity of the particular waste stream. The weights are given by the share of the mix, $\alpha$, that is being dumped. Whether the tax increases or decreases with the share, $\alpha$, depends on the detrimental effect of dumping the mix compared with dumping waste of type $i$. With $U_{B i}<U_{B w}<0$, the consumption tax increases when the share of mixed waste that is dumped increases. This reflects the fact that when waste of type $i$ is environmentally more damaging than the mix, its consumption is discouraged and therefore the quality of the mix is improved, reducing the effect of dumping the mix. For $U_{B i}>U_{B w}$, the reverse holds. As before, the refund for recycling is symmetric with the deposit after correction for the waste intensity of the good: comparing (12a) and (14a), we see that $t_{r i}^{*}=-t_{c i}^{*} / \psi_{i} \leq 0$. When $U_{B i}<U_{B w}$, the recycling subsidy increases when the share of mixed waste that is dumped, $\alpha$, increases. Environmentally more detrimental wastes are to be refunded at a higher rate.

Finally, the tax structure also induces households to separate waste for landfilling despite the effort involved. This requires an additional instrument, which is a deposit $t_{g i}^{*}$. Its level is derived from comparing (12b) and (14b), yielding $t_{g i}^{*}=n\left((1-\alpha) U_{B w}+\alpha U_{B i}-U_{G}\right) / \lambda$. This may seem counterintuitive, but by inducing households to separate waste for landfilling the government is able to shift the composition of the mix such that it becomes socially optimal to dump (a larger part of) the mix. This set of refunds can be used to 'extract' the most hazardous elements from the overall waste stream. Indeed, the larger the negative effect of dumping, $U_{B i}$, the higher the refund on separate landfilling. Moreover, with $U_{B i}<U_{B w}$, the refund on separate landfilling rises with the share of mixed waste that is dumped (again reducing the amount of hazardous waste in the mix). Note that to have separate landfill- 
ing at all, the refund on separate landfilling is (must be) larger than the refund on mixed landfilling. ${ }^{23}$

Note that this modified deposit-refund scheme still provides a first-best solution for this (local) optimum. The refund on separate and mixed landfilling provide proper incentives against separate and (potentially) suboptimal mixed dumping. It is also clear from this case that mixing has an effect only when the environmental effects of dumping differ between different types of waste. Indeed, if all wastes have identical environmental effects, $\forall i: U_{B i}=$ $U_{B}$, we are back in the original deposit-refund scheme. However, we now much better understand when it is optimal to apply different taxes. The difference in taxes on individual goods and wastes is larger when (i) the difference in environmental effects is larger and (ii) the share of mixed waste that is dumped is larger. The option of throwing goods and wastes with different-sized externalities into the same tax category in order to reduce administration costs (see Fullerton and Kinnaman 1995, p. 88) works better the smaller the difference between the environmental effects of dumping different wastes and the smaller the amount of mixed dumping. This is intuitive as well, because at higher levels of mixed dumping, grouping types of waste together becomes more detrimental as the most hazardous type of waste in the group is dumped more as well.

\subsubsection{Mixed dumping without separate landfilling}

The second subcase of mixing with mixed dumping does not allow for landfilling, i.e. assumes $g^{*}=0$. The results are identical to the one where $g^{*}>0$ except for the tax on separate landfilling. This tax must now be strictly larger than $n\left((1-\alpha) U_{B w}+\alpha U_{B i}-U_{G}\right) / \lambda$ in order to induce the household not to landfill separately. Since $n\left((1-\alpha) U_{B w}+\alpha U_{B i}-U_{G}\right) / \lambda<0$, we have that $t_{g i}^{*}=0$. This subcase may, for example, arise when the most hazardous types of waste are recycled (almost) completely. In that case no instrument has to shift the composition of the mix.

\section{Discussion and policy implications}

The previous section has shown that the deposit-refund system survives in a world where wastes can be mixed and illegal dumping is possible. Indeed, separated waste streams are more costly than mixed waste streams because of the effort of households in sorting waste streams from each other. Throwing all waste into the trash bin is the easiest way to get rid of waste as it avoids the trouble of keeping different boxes at home or walking or driving to the separate waste collection points. What is surprising, however, is not that mixing influences the design of optimal waste policy, but that it does not make first-best policy options impossible if one allows for effort as well. Our results show that the deposit-refund system is still a first-best solution even if effort is significant and mixing is possible. Only the level and number of deposits and refunds needed to reach the first-best are affected.

When households have the option to mix waste in order to avoid (too much) effort of separating waste streams, what would be the optimal waste policy for the government? The model suggests that governments better take appropriate notice of the role of separation effort and the option to dump mixed waste when designing their waste policy. Clearly trade-offs

\footnotetext{
23 Because of the Kuhn-Tucker structure of our optimal solution we have to check explicitly whether, at the above tax rates, there is no separate dumping, $\boldsymbol{b}^{*}=0$. It turns out that this condition is satisfied as long as the private costs of separate dumping are not too low compared with the private costs of landfilling and the private costs of mixed dumping. See Appendix section A.2.
} 
exist as to how much recycling and dumping is optimal and for what waste streams exactly. A careful design of the deposit-refund can be implemented to influence the composition of the mix (because this determines the externality of mixed dumping) and/or to stimulate recycling of particular waste streams. The design of this policy, however, is likely to depend on both endogenous and exogenous characteristics. To illustrate the role of the endogenous factors captured by our model, we shortly discuss three cases. First of all, if household waste does not contain 'too hazardous' wastes or all hazardous wastes can 'easily' be recycled, then some mixed dumping might be optimal. Apart from refunds to optimize recycling, a single refund on mixed landfilling would be sufficient to attract the optimal amount of mixed waste to the landfill and to prevent too much illegal dumping. ${ }^{24}$ Batteries are an example of easily extractable hazardous waste for which separation effort is small. Indeed, within the Netherlands an extensive and a quite successful collection system has been set up even without any refund system to stimulate cooperation by households.

Second, household waste might contain waste streams that are 'too hazardous' whereas its 'recyclability' is low. If this is the case, then it may be possible to extract some of the waste streams for separate landfilling in order to optimally allow some mixed dumping. One example is the collection of small chemical waste, which consists of used oil, paint and some types of light bulbs. Each separately extracted type of waste requires an additional landfilling refund. Together with the refund on mixed landfilled waste, the number of landfilling refunds will be between 2 and $N+1$. The exact number depends on how many waste streams should be 'extracted' from the mix in order to make mixed dumping more acceptable at the margin. The vicissitudes of special programs that have been introduced in several countries to keep small hazardous waste separate from other waste are illustrative for our model. For instance, the Dutch government stimulated the development of a drop-off system for hazardous waste (paint, thinner, etc.) from households. Under this program, a fine network of special collection facilities has been created including a driving drop-off point, the so-called 'chemo-cars'. ${ }^{25}$ In our view it is of little surprise that this separation policy has had limited success because it is very demanding in terms of effort. Our model suggest that the optimal 'extraction' policy for these types of waste requires a deposit to be paid when buying products that will later produce the hazardous waste, like paint and used oil. Households should receive a refund if this type of waste is disposed of at proper places (the collection facilities).

The third case is the one in which household waste contains 'too hazardous' wastes that have low recyclability and/or are demanding in terms of separation effort. In that case mixed dumping will be suboptimal and a single landfilling refund is necessary and sufficient to attain this (first-best) outcome. Note that one might still have optimal separate landfilling (or dumping) of certain waste streams, like mattresses or waste from construction sites. These types of waste cannot be mixed because of their size, i.e. they are 'non-mixable'.

Apart from these endogenous factors, the design of government policy is also likely to depend on a number of exogenous factors, like population density within the area (which affects both the environmental costs of dumping and the costs of recycling), the types of dwelling (houses or apartments), and transaction costs of implementing deposit-refund systems. For instance, high transaction costs makes separate landfilling refunds, like in our second case, less attractive. Separation costs are likely to be too high for households living

\footnotetext{
24 Note that the composition of the mix in the absence of separate dumping and separate landfilling is given by $\Psi c-r$. hence, a higher recycling rate of hazardous waste entails a lower environmental impact of dumping mixed waste.

25 These 'chemo-cars' drive through the local neighborhoods at pre-specified times. They are demanding in terms of effort in the sense that they require households to be at home at that particular time as the waste has to be personally handed over.
} 
in apartment buildings because usually not enough space will be available to temporarily stall different types of waste. Within the Netherlands, for instance, apartment buildings do not have separate bins for food or garden waste (because of the smell during periods of hot weather), whereas almost all houses do.

With both exogenous and endogenous factors in mind our results also explain some hard to understand empirical observations. For instance, Porter (2002, p.157) finds that no correlation exists between actual recycling rates (as well as recycling targets) and population density across US states. However, population density and effort may work against each other and thus explain the lack of correlation at state level. First, high population areas typically contain more apartments and hence a lower recycling rate ceteris paribus, because of the lack of suitable storage space. Second, high population areas typically entail lower recycling costs for both curbside and drop-off and hence higher recycling rates, again ceteris paribus. Finally, high populated areas will face higher costs of environmental dumping which makes policies to stimulate recycling more attractive (hence higher recycling rates).

Our findings also provide additional explanation for the likely existence of a natural limit on recycling even if households are willing to spend some effort 'for free'. According to our model, the more complex it is to get rid of one's separated waste stream and the higher the percentage of waste of a given type already recycled, the less likely households are willing to invest in holding more of their waste separate. This could explain the stabilizing recycling trends shown in Fig. 2 and also the difficulties in obtaining waste streams that are sufficiently pure. Taking a closer look at relatively homogeneous recycled waste streams, such as glass, reveals that such streams generally still comprise different qualities — for example, white, brown and green glass. In addition, they often contain impurities, i.e. minor fractions of other waste streams. This thwarts efforts for recycling, because an important condition for economically viable recycling is that the recycled streams are sufficiently pure. Whereas the production of colored glass requires separation of heat-resistant glass from other glass, the production of white glass requires additional separation of glass according to color. ${ }^{26}$ It is notoriously difficult to get sufficiently pure waste streams and the Dutch government even decided recently to allow municipalities to choose their own recycling policies in view of local differences in the quality of the recycled waste streams. Our model suggest that a clear alternative would be to use a deposit-refund system here to support existing recycling and disposal policies.

One last remark and potential objection to our paper is that we assume throughout this paper that the environmental effects of landfilled waste only depend on its overall level and not on its composition. Even though we belief that the design of modern landfills at least within the EU justifies this assumption, one should be careful to apply our results to countries where landfills do not meet these strict leakage regulations. Many landfills around the globe look more or less like dumping sites. Indeed, in countries where external effects of landfills clearly depend on the composition of the landfilled waste the government could still benefit from insights of the second case discussed before and consider deposit-refund systems to at least avoid landfilling mixed waste that includes waste streams that are 'too hazardous'. Obviously, this would only work if this separation is followed by proper recycling or landfilling that reduces externalities.

As a final remark, we like to point to some interesting extension of our paper. We have deliberately limited the discussion to cases without separate dumping, i.e. $\boldsymbol{b}^{*}=0$. The omitted case is rather unlikely, however, because households will typically be better off by

26 In the Netherlands, impurities in recycled paper and glass are respectively 5 and $1.2 \%$ of total weight. Also, a substantial part of organic waste does not meet environmental standards due to pollution with other types of waste and is therefore declared unfit for recycling (see AOO 2004a). 
dumping their waste mixed. This will not only save on effort (separation), but in general also save on the (higher) resources needed for illegal dumping. For the treatment of waste not produced at home (i.e. litter), the case of separate dumping may have relevance, however. This requires a different type of model as effort now is typically 'reversed'. For waste not produced at home, instantaneous littering saves on effort, whereas bringing waste to the waste bin, on the street or at home, now requires effort from the household.

\section{A Appendix}

\section{A.1 Mixing without dumping}

From (12d) and (14d), we have that $t_{c i}^{*}+t_{g 0}^{*} \psi_{i}=-n U_{G} \psi_{i} / \lambda$. We have to check whether there exist taxes $t_{c i}^{*}$ and $t_{g 0}^{*}$ such that equations (14b), (14c) and (14e) are satisfied with inequality. First, check under what conditions the first-order condition for $g_{i}$ is satisfied with strict inequality. Substituting (14d) into (14b), we must have

$$
\omega_{g i} U_{e i}+\lambda t_{g 0}^{*}-\lambda t_{g i}^{*}<0
$$

Since $U_{e i}<0$, a sufficient condition is that $t_{g 0}^{*}<t_{g i}^{*}$.

Second, check (14c). Substituting (14d) into (14c), we must have

$$
\omega_{b i} U_{e i}+\lambda f_{k c i} / \gamma+\lambda t_{g 0}^{*}<n\left(U_{G}-U_{B i}\right)+\lambda t_{g 0}^{*}<0
$$

where the first inequality follows from the observation that (12c) and (12d) must hold with inequality and equality respectively, since $b_{i}^{*}=0$ and $m_{i}^{*}>0$. Separate dumping will be zero when the second inequality in (17) is satisfied. This is the case as long as $t_{g 0}^{*}<$ $n\left(U_{B i}-U_{G}\right) / \lambda$. Since this condition must hold for all types of waste, we have

$$
t_{g 0}^{*}<\min _{i} n\left(U_{B i}-U_{G}\right) / \lambda=n\left(U_{B 1}-U_{G}\right) / \lambda
$$

Finally, check under what conditions (14e) is satisfied with inequality. From $\alpha^{*}=0$, we have that (12e) must hold with inequality,

$$
\Omega_{m} \boldsymbol{m} \boldsymbol{U}_{\boldsymbol{e}}<n U_{G} \boldsymbol{\iota} \boldsymbol{m}-n \boldsymbol{m} \boldsymbol{U}_{\boldsymbol{B}}-\delta_{i} f_{k c i}^{i} \iota \boldsymbol{m} / \gamma
$$

Rearranging terms and using $\delta_{i}=\lambda$, we have

$$
\Omega_{m} \boldsymbol{m} \boldsymbol{U}_{\boldsymbol{e}}<-\lambda\left(f_{k c i}^{i} / \gamma-\frac{n\left(U_{G}-U_{B w}\right)}{\lambda}\right) \iota \boldsymbol{m}
$$

where $U_{B w}$ is defined as $\boldsymbol{m} \boldsymbol{U}_{\boldsymbol{B}} / \boldsymbol{\imath} \boldsymbol{m}$, the weighted disutility of dumping mixed waste with the weights given by the quantity of each waste in the mix. Hence, as long as $t_{g 0}^{*}<$ $n\left(U_{B w}-U_{G}\right) / \lambda(14 \mathrm{e})$ is satisfied. This requirement is redundant, however, as it is satisfied whenever (18) is satisfied. 
A.2 Mixing with mixed dumping

We have to check whether there is no separate dumping at taxes

$$
\begin{aligned}
t_{c i}^{*} & =-n \psi_{i}(1-\alpha) U_{B w} / \lambda-n \psi_{i} \alpha U_{B i} / \lambda \\
t_{r i}^{*} & =n(1-\alpha) U_{B w} / \lambda+n \alpha U_{B i} / \lambda \\
t_{g i}^{*} & =n(1-\alpha) U_{B w} / \lambda+n \alpha U_{B i} / \lambda-n U_{G} / \lambda \\
t_{g 0}^{*} & =n\left(U_{B w}-U_{G}\right) / \lambda
\end{aligned}
$$

Separate dumping will not occur if the household prefers either separate landfilling or mixing waste to separate dumping. First, check under what conditions separate landfilling is preferred over separate dumping. Substituting (14b) into (14c) and rearranging terms gives:

$$
-\frac{\omega_{b i} U_{e i}}{\lambda}>-\frac{\omega_{g i} U_{e i}}{\lambda}+f_{k c i}^{i} / \gamma+t_{g i}^{*}
$$

i.e. the 'total cost' of separate dumping should be larger than the 'total cost' of separate landfilling. This condition is satisfied whenever the effort intensity of separate dumping, $\omega_{b i}$, is sufficiently larger than the effort intensity of separate landfilling, $\omega_{g i}$. Notice that $\omega_{b i}>\omega_{g i}$ as separate dumping requires both effort to separate waste and effort to dump the waste, whereas separate landfilling requires the first only.

In a similar way it can be shown that mixing is preferred over separate dumping as long as the effort intensity of separate dumping, $\omega_{b i}$, is sufficiently larger than the effort intensity of mixed dumping, $\alpha \omega_{m i}$.

\section{References}

Aadland D, Caplan AJ (2003) Willingness to pay for curbside recycling with detection and mitigation of hypothetical bias. Am J Agricult Econ 85:492-502

Aalbers RFT, Vollebergh HRJ (2005) An economic analysis of mixing wastes. Tinbergen Institute Discussion Paper No. 2005-094/3

Ackerman F (1997) Why do we recycle? Markets, values, and public policy. Island Press, Washington DC

Afval Overleg Orgaan (2004) www.aoo.nl;www.senternovem.nl/uitvoeringafvalbeheer/

Beatty T, Berck P, Shimshack J (2006) Curbside recycling in the presence of alternatives, mimeo

Calcott P, Walls M (2000) Can downstream waste disposal policies encourage upstream "design for the environment"?. Am Econ Rev 90(2):233-237

Choe C, Fraser I (1999) An economic analysis of household waste management. J Environ Econ Manage 38:234-246

Choe C, Fraser I (2001) On the flexibility of optimal policies for green design. Environ Resour Econ 18:367371

Dijkgraaf E, Gradus R (2004) Cost savings in unit based pricing of household waste: the case of the Netherlands. Resour Energy Econ 26:353-371

Dijkgraaf E, Vollebergh HRJ (2004) Burn or Bury? A social cost comparison of waste disposal methods. Ecol Econ 50:233-247

Eichner T, Pethig R (2001) Recycling, producer responsibility and centralized waste management. J Environ Econ Manage 41:109-134

Eichner T, Pethig R (2003) Corrective taxation for curbing pollution and promoting green product design and recycling. Environ Resour Econ 25(4):477-500

Fullerton D, Kinnaman TC (1995) Garbage, recycling, and illicit burning or dumping. J Environ Econ Manage 29:78-91

Fullerton D, Wolverton A (2000) Two generalizations of a deposit-refund system. Am Econ Rev 90(2):238242

Fullerton D, Wu W (1998) Policies for green design. J Environ Econ Manage 36:131-148 
Huhtala A (1999) How much do money, inconvenience and pollution matter? Analysing households' demand for large-scale recycling and incineration. J Environ Manage 55:27-38

Jenkins RJ, Martinez SA, Palmer K, Podilsky MJ (2003) The determinants of household recycling: a materialspecific analysis of recycling program features and unit pricing. J Environ Econ Manage 45:294-318

Porter RC (2002) The economics of waste. Resources for the Future, Washington DC

Shinkuma T (2003) On the second-best policy of households' waste recycling. Environ Resour Econ 24:77-95

Statistics Netherlands, Statline, statline.cbs.nl/ 